DOI: https://doi.org/10.24867/11GI02Gasparevic

\title{
ULOGA SAVREMENIH RAČUNOVODSTVENO-SOFTVERSKIH PROGRAMA NA PROCES REVIZIJE
}

\section{THE ROLE OF MODERN ACCOUNTING SOFTWARE ON THE AUDIT PROCESS}

\author{
Milena Gašparević, Fakultet tehničkih nauka, Novi Sad
}

\section{Oblast- INDUSTRIJSKO INŽENJERSTVO I MENADŽMENT}

\begin{abstract}
Kratak sadržaj- Tema rada nastoji da prikaže kako se savremene tehnologije mogu kombinovati i međusobno dopunjavati $i$ sve to u korist razvoja prakse revizije. Cilj rada je da se ukaže pažnja na široke mogućnosti koje pružaju računovodstveno-softverska rešenja, koja su tu da posao revizora svedu na kraće vreme trajanja i lakšu obradu. Tačnije u radu će se fokus zadržati na novonastalim računovodstveno softverskim alatima, koji predstavljaju veliku podršku procesu revizije.
\end{abstract}

Ključne reči: operativna revizija, informacione tehnologije, telekomunikacione tehnologije, revizorski alati

Abstract- The theme of the paper seeks to show how modern technologies can be combined and complement each other in order to develop the practice of auditing. The aim of the paper is to draw attention to the wide possibilities offered by accounting software solutions, which are to reduce the work of the auditor for a shorter period of time and easier processing. More precisely, the focus will be on the new accounting software tools, which provide great support for the audit process.

\section{UVOD}

Kao predmet istraživanja rada, biće objašnjena uloga CAAT's alata, koji su relativno novi alati i predstavljaju visokospecijalizovanu uslugu koja pruža mogućnosti standardizovanja revizorskih poslova, kao i njihovo olakšavanje.

Osnovna karakteristika revizije sadržana je u njenom glavnom cilju, a to je da se detaljno ispita postojanje potencijalnih kriminalnih radnji, kao i da se u slučaju otkrivanja obezbedi jednoznačni materijalni dokazi za te radnje.

Tradicionalna revizija stavlja akcenat na uočavanje grešaka i prevenciju delovanjem sistema interne kontrole, pri čemu revizor najčešće koristi metod uzorkovanja. Za takvo ispitivanje, biće potrebno poznavanje pomenutih programa i alata.

\section{NAPOMENA:}

Ovaj rad proistekao je iz master rada čiji mentor je bio dr Branislav Nerandžić, redovni prof.

\section{OPERATIVNA REVIZIJA}

Danas, sve više prisutna i pominjana reč- revizija, potiče od latinskog izraza „revisio“, što na srpskom jeziku označava ponovno viđenje, ponovno gledanje, obnova procesa i na kraju, sa posebnim naglaskom poslednji pregled sloga pred štampu [1].

Ova značenja nas navode, da na reviziju, kao oblast, gledamo sa šireg aspekta, koji sa sobom povlači i nekoliko osnovnih definicija.

Revizija u poslovanju, prema rečima S. Kukoleča, predstavlja „svaku sistemsku i detaljno sprovedenu naknadnu kontrolu poslovanja organizacije“" [2].

Takođe, ističe se i revizija finansijskog poslovanja, koja obuhvata detaljno ispitivanje čitavog poslovanja $u$ određenom periodu ili ispitivanje jednog užeg sektora. Možemo reći da ,revizija ima za cilj utvrđivanje stepena korespodentnosti između datih tvrdnji i nekog prethodno definisanog kriterijuma, kao i saopštavanje rezultata tih upoređivanja zainteresovanim korisnicima“ [3].

Posmatrajući reviziju sa aspekta sudstva, kaže se da je ona „obnova sudskog spora, na zahtev jedne od strana $u$ sporu, na osnovu novih dokaza“, dok sa gledišta administracije ona predstavlja ,izmenu i dopunu zakona i drugih postojećih pozitivno pravnih propisa.

U publikovanju se kaže da je revizija ,poslednji pregled autorskog dela i štampanih stvari sa odobrenjem za štampu.

Dakle, kada je na početku rečeno da je reč „revizija“ danas veoma prisutna, to znači da se utkala u više sfera, počevši od manjih oblasti, pa sve do velikog sistema kao što je država.

Treba napomenuti, da posao revizije nikako ne obavljaju mašine, računari i slično, to je isključivo posao za ljude, dok se mašine tu pojavljuju samo kao alat.

Prema tome, možemo zaključiti da revizija, bilo gde i bilo u kom smislu, predstvalja intelektualnu aktivnost. Lice koja obavlja tu aktivnost naziva se revizor, isključivo $u$ slučaju računovodstvenog iskazivanja finansijskog poslovanja.

\section{INFORMACIONE TEHNOLOGIJE}

Današnjica uveliko zavisi od postojanja bilo koje vrste kompjuterizovanosti informacionih sistema, bez njih se ne 
može zamisliti odvijanje svakodnevnih aktivnosti poslovnih subjekata, kao ni dugoročni opstanak istih.

Brzina protoka informacija danas je veoma bitna, a ukoliko želite da sa brzinom imate i tačne, pouzdane informacije, znači da su vam neophodni računari. Primenom računara, poslovni subjekti obezbeđuju sebi efikasnost i kompetitivnost poslovanja, bez čega se danas ne možete takmičiti na tržištu.

Stoga, poželjno je posedovati adekvatan informacioni sistem, tako organizovan, da podmiruje potrebe poslovnog subjekta.

Bez obzira na veličinu, tip i delokrug preduzeća, njegov informacioni sistem se zasniva na tri osnovne aktivnosti: ulazu, obradi i izlazu podataka. Ulaz obuhvata prikupljanje sirovih podataka koji potiču iz organizacije ili njenog okruženja. Obradu čini konvertovanje sirovih podataka u primereniju i korisniju formu. Izlaz uključuje transferisanje obrađenih informacija ka njihovim korisnicima.

Podaci se prikupljaju tako što se iz dokumentovanihpapirnih formata, direktno prekucavaju u kompjuterski sistem putem tastature ili nekog drugog sredstva, kao što je na primer bar-kod čitač. To podrazumeva aktivnosti beleženja, kodiranja, klasifikovanja i izmene, koje osiguravaju korektnost i potpunost zahtevanih zadataka.

Obrada teče tako što se podaci organizuju putem kalkulacija, upoređivanja, sumiranja i sortiranja u neki koristan oblik i korisnicama razumljiv. Nakon toga slede izlazne aktivnosti, nakon kojih se rezultati obrade mogu koristiti za informisanje, odlučivanje i kontrolu.

Prema navedenom, vidimo da informacione tehnologije danas pretežno vežemo za pojavu kompjutera (pored smart telefona i drugih uređaja) koja znatno olakšava kako posao računovođa tako i posao revizora. Možemo sa sigurnošću da kažemo da je informaciona tehnologija daleko doprinela oblasti revizije.

\section{TELEKOMUNIKACIONE TEHNOLOGIJE}

Iako čovek služi da se podaci ubace u sistem, ipak je mašina ta koja velikom brzinom sređuje podatke i izvodi operacije na programiran način.

Ovakav način rada kompjutera, služi revizoru na korist, jer on tada stiče poverenje $u$ ispravnost računovodstvenih podataka. Revizor ne mora da sprovede veliki broj testova kada se o računovodstvenim podacima brine kompjuter, što mu mnogo olakšava i ubrzava rad.

Što se tiče detaljnih zapisa, kompjuteri imaju sposobnost održavanja detaljnijih i aktuelnijih zapisa.

Ova mogućnost je od velikog značaja za revizore pri izvođenju kontrolnih i suštinskih testova. Priroda kompjuterske obrade podrazumeva programske kontrole, koje mogu biti $u$ vidu pristupa traženja lozinke pri pretrage na računaru, po podacima, programima ili datotekama.

Istovremeno evidentiranje na više računa i u više datoteka podrazumeva da računar sam povlači konta koja bivaju promenjena, na primer prilikom nabavke, računar će prepoznati da treba da knjiži promenu i na kontu dobavljača i na kontu zaliha. Zato revizor mora da obrati pažnju na simultano evidentiranje, jer jedna greška može da se primeni na više računa i više datoteka.

Računovodstvene informacije sve više bivaju obrađivane pomoću kompjutera, bez obzira o kakvoj se organizaciji radi. Stepen primene varira od jedne ili dve samostalne aplikacije (na primer, fakturisanje ili obračun plata) pa sve do mnoštva aplikacija koje su potpuno integrisane $\mathrm{u}$ sistem kompjuterskog vođenja dvojnog knjigovodstva, uključujući i kompjutersko generisanje finansijskih izveštaja po potrebi.

\section{REVIZORSKI ALATI}

Karakteristike računara kao sredstva za procesiranje podataka i informacija, sve više navode na njegovu primenu i u oblasti revizije, gde će važiti za jedan od osnovnih alata revizora.

Brzina, preciznost, sposobnost masovnog računanja i mogućnost memorisanja ogromnih količine podataka, kompjuter direkno svrstava među najpouzdanije alate koji su danas neophodni.

$\mathrm{Na}$ osnovu svega izloženog jasno je da revizor može korišćenjem računara kao alata u znatnoj meri proširiti i produbiti kako intenzivnost, tako i efikasnost revizije. U tu svrhu su razvijene tehinke revizije uz pomoć kompjutera.

Najznačajnije tehnike revizije su: test podaci, integrisani test podaci, paralelna simulacija $\mathrm{i}$ onlajn revizorski monitor [1].

Za realizaciju testiranja uz pomoć test podataka, revizor mora kreirati izmišljene podatke koji će biti obrađeni od strane kompjuterskog sistema, pod nadzorom revizora.

Test podaci treba da sadrže podatke za koje se očekuje da budu obrađeni od strane sistema, kao i podatke koje sistem treba da odbaci jer nisu u skladu sa kontrolnim procedurama.

Na ovaj način, revizor utvrđuje da li kompjuterski sistem radi po pravilima, na primer da li dobro obračunava sate radnicima, da li na osnovu njih dobro obračunava bruto zarade radnika i slično.

Sa druge strane, kada revizor ubaci podatke koje sistem treba da odbaci, revizor se uverava da sistem prepoznaje višak svog posla, odnosno da te podatke ne svrstava negde drugde gde nisu potrebni. Ukoliko sistem prepozna takve podatke, mora da javi nepravilnosti i onemogući unos.

Na slici 1. prikazan je postupak test podataka:

Integrisani test podaci predstavljaju tehnike test podataka. Razlika se krije $\mathrm{u}$ tome što se, umesto provere funkcionisanja kompjuterskog sistema dok ga klijent ne koristi, kod primene integrisanih test podataka simulirani podaci se pridodaju pravim podacima radi zajedničke obrade, slika 2. 


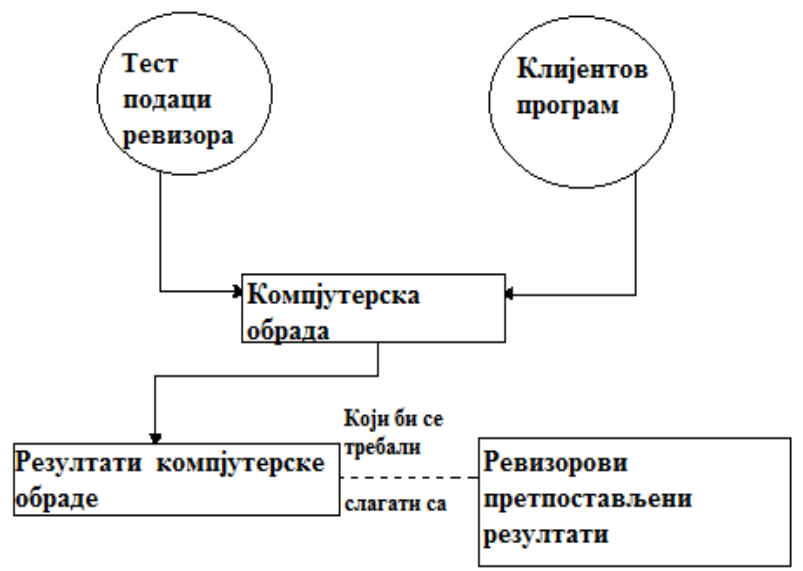

Slika 1: Test podaci; Izvor [1]

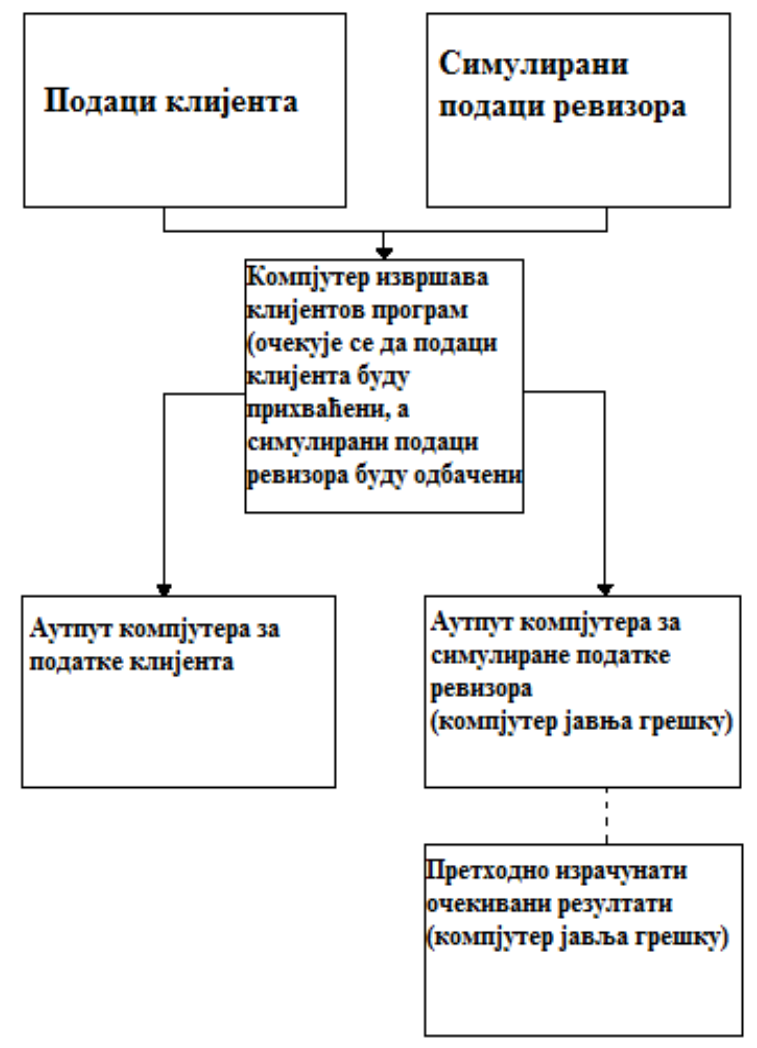

Slika 2: Integrisani test podaci; Izvor [1]

Kao i kod test podataka, dobijeni kompjuterski podaci se upoređuju sa prethodno izračunatim, očekivanim rezultatima.

Radi izbegavanja kontaminacije stvarnih podataka klijenta, potrebno je osmisliti sistem razdvajanja i razlikovanja simuliranih podataka, kako bi se oni mogli ukloniti iz kompjuterskog sistema.

Uviđa se prednost primene integrisanih test podataka $u$ tome što omogućuju revizoru da testira obradu podataka u stvarnim uslovima rada.

Takođe, prednost je i što kompjuter klijenta nije u potpunosti imobilisan u obavljanju svakodnevnih poslova za vreme dok se testiranje vrši (za razliku od test podataka).

Sledi prikaz prethodnog objašnjenja:
U paralelnoj simulaciji, revizor koristi prave stvarne podatke, što predstavlja veliku razliku od prethodne dve tehnike revizije.

U paralelnoj simulaciji podaci se obrađuju i klijentovim i revizorovim programom, a zatim se dobijeni rezultati međusobno upoređuju radi otkrivanja razlika.

Prednost primene paralelne simulacije je $\mathrm{u}$ tome što revizijski programi mogu koristiti dodatne kontrole. Takođe, paralelna simulacija može biti veoma korisna za proveru izračunavanja amortizacije, kamate, poreza, visine odbitaka od zarada zaposlenih i drugo.

$\mathrm{Na}$ slici 3. dat je prikaz revizijske tehnike paralelne simulacije.

Onlajn unos podataka i obrada znači da se transakcije unose i obrađuju u momentu njihovog nastanka.

Međutim, sistemi onlajn unosa i obrade u realnom vremenu zasnivaju se na drugačijim principima, koji zahtevaju specifične oblike testiranja.

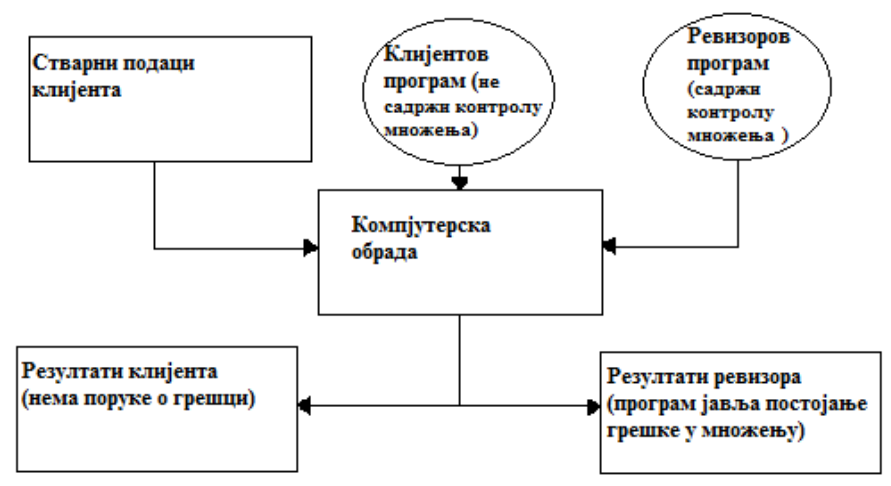

Slika 3: Paralelna simulacija; Izvor [1]

\section{ZAKLJUČAK}

Tamna strana „evolucije“ računovodstva dovela je do pojave tzv. „kreativnog“ računovodstva čiji je prevashodni cilj manipulisanje izveštajima u cilju stvaranja lažne slike poslovanja kompanije.

Pojavom takvih manipulacija, pojavljuju se i odgovarajući alati koji sprečavaju prolazak greške odnosno nepravilnosti $\mathrm{u}$ dalji posao, tako da je praktično nemoguće nasamariti revizora koji obavlja pregled finansijskih izveštaja.

Neminovno je da se posao revizora znatno izmenio zbog pojave računara kao osnovnog alata današnjice, kako u obimu aktivnosti kojim sada treba da raspolaže, tako i u tehnikama koje mora da savlada kako bi uspeo da se održi u poslu. Ipak se može zaključiti da pojavom računovodstveno-softverskih rešenja, revizor danas lakše i brše ulazi u nepravilnosti koje su počinjene od strane klijenta, zato što su takva softverska rešenja stvorena sa posebnom svrhom, a to je da traže nepravilnosti u poslovanju, što je u samom radu i opisano.

Dakle, posao revizora je veoma osetljiv i zavisi isključivo od njegovih veština i znanja, a u svemu tome danas revizor može da sebi priušti brzu i savremenu tehnologiju koja će njegov posao još više ubrzati a u većini slučaja i olakšati. 
Ne treba zanemariti da sa povećanjem stepena tehnologije, poslovni klijenti takođe mogu u svom poslovanju imati naprednu tehnologiju što dodatno može usporiti revizora u svom poslu, jer mu treba više vremena i alata da proprati sva dešavanja u klijentovoj kompaniji.

\section{LITERATURA}

[1] Andrić, M., Krsmanović, B., Jakšić D., Revizija teorija i praksa, (2009), Ekonomski fakultet Subotica, štampa Novi Sad

[2] Kukoleča, S., Organizovani poslovni leksikon izraza, pojmova i metoda, (1990), Zavod za ekonomske ekspertize Beograd, štampa Beograd

[3] David N. Ricchiute, D., (1989) Auditing, concepts and standards, Boston, Published 1989 by South-Western

Pub. Co. in Cincinnati, ISBN: 9780538838832

\section{Kratka biografija:}

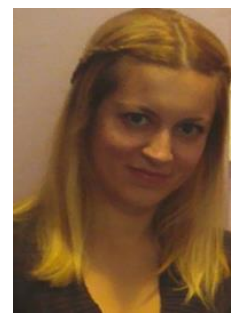

Milena Gašparević rođena je 03.12.1983. godine u Bačkoj Topoli. Zvanje strukovnog ekonomiste stiče 2010. godine na Visokoj poslovnoj školi u Novom Sadu. Zatim, 2014. godine upisuje smer IIM na Fakultetu tehničkih nauka u Novom Sadu, radi dokvalifikacija na osnovnim akademskim studijama koje završava 2016. godine odbranom diplomskog rada iz oblasti-Operativna revizija. Iste godine, na istom fakultetu upisuje master akademske studije, smer-Investicioni menadžment. 